\title{
EFIKASI DAUN JATI CINA DALAM MENGATASI KONSTIPASI
}

\author{
Qotrunnada Salsabila
}

Fakultas Kedokteran, Universitas Lampung, Jl. Prof. DR. Ir. Sumatri Brojonegoro No.1, Gedong Meneng, Kec. Rajabasa, Kota Bandar Lampung, Lampung, Indonesia 35145 nadasalsa2112@gmail.com (+6285933716217)

\begin{abstract}
ABSTRAK
Konstipasi merupakan gangguan gastrointestinal yang umum terjadi pada seluruh tingkat usia dan gejalanya dapat secara signifikan mempengaruhi kualitas hidup penderita. Dewasa ini, teh maupun kapsul berisi serbuk daun jati cina banyak dipasarkan kepada masyarakat sebagai produk laksatif untuk penanganan konstipasi juga sebagai penurun berat badan. Pada daun jati cina dapat ditemukan beberapa komponen bioaktif yang berperan dalam manfaat-manfaat kesehatannya seperti senyawa antraquinoid (senosida (A, B, C, dan D), fenol, flavonoid, sakarin, turunan naftalen, fitosterol, serta senyawa-senyawa lain. Metode analisis yang digunakan adalah dengan studi literatur dengan cara meringkas topik diskusi lalu membandingkan hasilnya dalam artikel, dengan kriteria inklusinya adalah jurnal-jurnal saintifik nasional dan internasional dalam sepuluh tahun terakhir (2011-2020) yang diakses dari situs-situs terpercaya. Melalui hasil pencarian pada situs NCBI, Elsevier, Pubmed, dan lainnya dengan kata kunci yang digunakan berupa daun jati cina, laxative, alexandrian senna, weight-loss, Senna alexandrina Mill., didapatkan 12.549 artikel namun hanya 30 artikel yang dianggap relevan. Hasil yang didapatkan adalah bahwa meskipun daun jati cina menunjukkan manfaat yang besar dalam menangani konstipasi maupun pembersihan usus, tetapi perlu diperhatikan juga bahwa penggunaannya yang berlebih berpotensi memberikan efek toksisitas pada manusia.
\end{abstract}

Kata kunci: daun jati cina; konstipasi; laksatif; senna alexandrina Mill

\section{EFFICACY OF SENNA LEAVES ON TREATING CONSTIPATION}

\begin{abstract}
Constipation is a common gastrointestinal disorder among all age groups and the symptoms can significantly affect patient's quality of life. To date, both tea and powdered leaves stored in capsules of senna have been massively marketed as a laxative to treat constipation and a weightloss product. There are a plenty of bioactive compounds which contribute to its health benefits that can be found in senna leaves, such as antraquinoid compounds (sennoside $(A, B, C$, and $D$ ), phenols, flavonoids, saccharides, naphthalene derivatives, phytosterols, and other compounds. The analysis was carried out by using literature studies through summarizing the topic of discussion then comparing the results presented in the article, with the inclusion criteria of national and international scientific journals in the last ten years (2011-2020) accessed through trusted sites. Through the search results on the NCBI, Elsevier, Pubmed, and other sites with keywords used were senna leaves, laxative, alexandrian senna, weight-loss, Senna alexandrina Mill., 12,549 articles were obtained but only 30 articles were considered relevant. The result obtained showed that although senna leaves show several marvelous health benefits in treating constipation and colon-cleanse, we too must consider that its excessive usage can potentially give toxic effects to human.
\end{abstract}

Keywords: constipation; laxative; senna leaves; Senna alexandrina Mill 


\section{PENDAHULUAN}

Konstipasi adalah kondisi di mana feses mengeras sehingga susah dikeluarkan melalui anus, dan menimbulkan rasa terganggu atau tidak nyaman pada rektum. Konstipasi dapat disebabkan oleh berbagai hal, seperti kurangnya asupan serat, kurang asupan air, pengaruh obat yang dikonsumsi, pengaruh dari penyakit yang diderita, hingga akibat kurang aktivitas fisik (Brown et al., 2011). Konstipasi dapat terjadi pada semua lapisan usia, yang pada umumnya ditandai dengan frekuensi buang air besar yang rendah (kurang dari 3 kali dalam satu minggu atau 3 hari tidak buang air besar dan diperlukan mengejan secara berlebihan) (Dharmika, 2014; A. D. K. Sari \& Wirjatmadi, 2017). Saat defekasi akan menimbulkan rasa nyeri pada perut ketika buang air besar. Hal tersebut dapat memicu tingkat stres pada penderita konstipasi akibat rasa ketidaknyamanan (Claudina, Rahayuning, \& Kartini, 2018). Umumnya konstipasi dianggap sebagai hal biasa yang terjadi sesekali dan tidak berdampak pada gangguan sistem tubuh, namun apabila dibiarkan tidak ada penanganan dan terjadi secara berulang dalam kurun waktu yang lama akan mengakibatkan komplikasi (Setyani, 2012).

Berdasarkan survei yang dilakukan, prevalensi konstipasi di Asia (direpresentasikan oleh Korea, Cina, dan Indonesia) diperkirakan terjadi sebanyak $15-23 \%$ pada perempuan dan $11 \%$ pada laki-laki. Sebagai perbandingan dengan survei yang sama, ditemukan prevalensi yang lebih rendah di Jerman, Italia, dan Inggris yaitu sebesar $7-11 \%$ pada perempuan dan < 5\% pada laki-laki (Gwee et al., 2013). Di Indonesia sendiri terdapat sebanyak 3.857.327 jiwa yang mengalami konstipasi sesuai data International Database US Census Bureau pada tahun 2003 (A. Sari, 2016).

Tumbuhan jati cina, yang banyak dikenal dengan satu paying besar dalam genus senna, tersusun atas 500 spesies di mana 26 spesies dari genus Cassia telah dilaporkan memiliki turunan anthracene, baik dalam bentuk bebas maupun dalam bentuk glikosida. Di antara spesies-spesiesnya, Cassia angustifolia dan Cassia acutifolia adalah yang sering diteliti karena aktivitas laksatifnya dan juga karena tersedia dalam jumlah yang besar. Spesies lain yang telah diketahui juga memiliki aktivitas laksatif adalah Cassia fistula, Cassia obovata, Cassia dentate, Cassia sofara, Cassia sieberiana, Cassia podocarpa, dan Cassia alata (Ramchander, Jalwal, \& Middha, 2017).

Chien, Chu, dan Lee (2010) dalam penelitiannya mengemukakan bahwa salah satu spesies jati cina, Cassia angustifolia Vahl., mengandung anthracenedione. Pada dasarnya, anthracenedione atau anthraquinone berfungsi sebagai laksatif untuk mengobati konstipasi akut. Senosida akan mempercepat gerakan hasil pencernaan di usus sehingga menaikkan volume hasil pencernaan dan meningkatkan gerakan peristaltik usus terutama di bagian kolon kiri dan sigmoid. Dengan menghambat aktivitas sodium potasium adenosine triphosphatase di enterosit, sodium, klorida, dan air yang terabsorpsi oleh usus menjadi sedikit sehingga feses menjadi lembek. Peningkatan motilitas usus juga akan memperpendek durasi makanan di usus (Vidiastri, 2012).

Daun jati cina relatif aman apabila dikonsumsi dalam dosis yang rendah dalam jangka waktu yang singkat pada 
penderita konstipasi (Blumenthal, Brinckmann, \& Goldberg, 2000; Soyuncu, Cete, \& Nokay, 2008). Apabila dikonsumsi dalam dosis yang besar dan/atau dalam jangka waktu yang panjang, telah banyak dilaporkan terjadi beberapa efek samping yang cukup serius seperti ketergantungan laksatif, diare hebat, hipokalemia, dan kerusakan hepar (Balasankar, Vanilarasu, Preetha, Umadevi, \& Bhowmik, 2013; Gattuso \& Kamm, 1994). Namun, tak dapat dipungkiri juga bahwa konsumsi pertama kali dalam dosis yang rendah pun dapat menimbulkan beberapa efek samping yang ringan seperti diare ringan dan nyeri perut.

Dikarenakan telah banyaknya konsumsi daun jati cina, baik dalam bentuk serbuk yang dikapsulkan atau pun dalam bentuk teh, namun masih sedikit pemahaman masyarakat terhadap efikasi dan efek samping apa saja yang mungkin timbul, maka perlu dilakukan penelitian yang bertujuan mempelajari efikasi daun jati cina dalam menangani konstipasi melalui studi literature review.

\section{METODE}

Penelitian ini menggunakan studi literature review, dengan langkah analitis mencari dan menggabungkan intisari serta menganalisis fakta dari berbagai sumber ilmiah yang sesuai kriteria valid dan akurat dengan tujuan untuk menambah pemahaman topik yang dibahas. Tinjauan literatur menyajikan ringkasan berupa publikasi paling relevan kemudian membandingkan hasil yang disajikan dalam makalah. Pengumpulan suumber data yang digunakan dalam artikel ini terdiri dari sumber data primer berupa jurnal ilmiah, baik nasional maupun internasional dan sumber tersier berupa situs-situs web terpercaya seperti Pubmed, NCBI, Elsevier, dan situs-situs lainnya. Kata kunci yang digunakan di antaranya adalah daun jati cina, senna leaves, laxative, alexandrian senna, weight-loss, Senna alexandrina Mill., dan sebagainya. Kriteria inklusi pada jurnal ini yaitu jurnal-jurnal saintifik nasional dan internasional dalam sepuluh tahun terakhir (2011-2020) yang diakses dari situs-situs terpercaya artikel yang membahas tentang manfaat daun jati cina dalam menangani konstipasi.

Melalui hasil pencarian pada situs-situs web terpercaya menggunakan kata-kata kunci terlampir, ditemukan sebanyak 12.549 artikel namun hanya 30 artikel yang dianggap relevan pada studi ini. Analisis dilakukan dengan menggunakan metode systematic literature review dengan cara menekaah, mengidentifikasi, mengkaji, dan menyajikan data yang didapat. Sebelum proses penyajian, terlebih dahulu dilakukan penggabungan, pengkajian kembali materi yang diterangkan sebelumnya, dan bandingkan hasil yang disajikan artikel untuk selanjutnya dilakukan penarikan kesimpulan yang sesuai.

\section{HASIL}

Salah satu komponen utamanya adalah senyawa senosida yang dimetabolisme oleh bakteri di usus besar menjadi metabolit aktif rheinanthrone (Lemli, 1988). Daun jati cina mengandung dua glikosida kristalin aktif, senosida A dan B. Daun jati cina juga mengandung senosida $\mathrm{C}$ dan $\mathrm{D}$, yang merupakan hetero-dianthrone dari masing-masing rhein dan aloe-emodin. Kemudian, beberapa senyawa monoanthrone lain pun dapat ditemukan dalam kadar yang sedikit, seperti aloe emodin mono- dan diglukosida (aloeemodin-dianthrone 
diglikosida) dan rhein monoand diglukosida (rhein-anthrone-8glycoside, rhein-8-diglucoside). (Ramchander et al., 2017). Struktur kimiawi dasar dari masing-masing senosida dijabarkan pada Tabel 1.

Hasil uji penapisan kualitatif pada penelitian yang dilakukan oleh Ahmed et al. (2016) terhadap jati cina Cassia angustifolia membuktikan adanya steroid, alkaloid, tannin termasuk phlobatannin, monoterpene, flavonoid, coumarin, glikosida, saponin, diterpene, anthraquinone, dan fenol. Total senyawa fenol dan flavonoid pada ekstrak aqueous maupun ekstrak organik dinilai pada penelitian ini. Senyawa fenol dinilai dengan cara menentukan kurva standar menggunakan konsentrasi berbeda dari GAE (Gallic Acid Equivalent), sedangkan senyawa flavonoid dinilai dengan cara menentukan kurva standar menggunakan konsentrasi berbeda dari

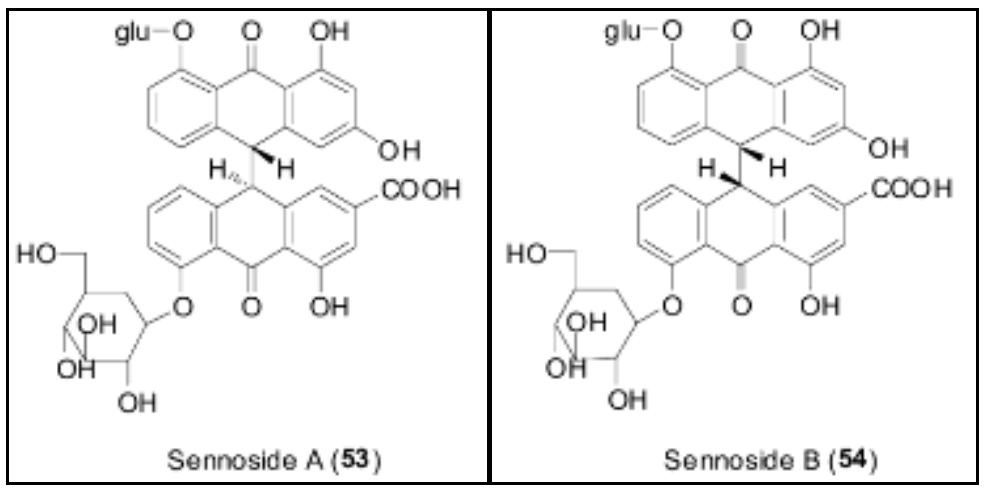

Gambar 1. Struktur kimia senosida A dan senosida B (Wang, Gao, Menéndez-Arias, Liu, \& Zhan, 2017)

Tabel 1.

Struktur kimiawi dasar dari masing-masing senosida pada daun jati cina (Ramchander et

\begin{tabular}{lllll}
\multicolumn{5}{c}{$a l ., 2017)$} \\
\hline No. & $\mathrm{R} 1$ & $\mathrm{R} 2$ & $10-10$ & Glikosida \\
\hline 1. & $\mathrm{COOH}$ & $\mathrm{COOH}$ & Trans & Senosida A \\
\hline 2. & $\mathrm{COOH}$ & $\mathrm{COOH}$ & Meso & Senosida B \\
\hline 3. & $\mathrm{CH}_{2} \mathrm{OH}$ & $\mathrm{COOH}$ & Trans & Senosida C \\
\hline 4. & $\mathrm{CH}_{2} \mathrm{OH}$ & $\mathrm{COOH}$ & Meso & Senosida D \\
\hline
\end{tabular}

Tabel 2.

Nilai kuantitatif senyawa fenol dan senyawa flavonoid dari beberapa ekstrak $C$. angustifolia (Ahmed et al., 2016)

\begin{tabular}{lccc}
\hline No. & $\begin{array}{c}\text { Ekstrak daun jati cina } \\
(400 \mu \mathrm{g} / \mathrm{mL})\end{array}$ & $\begin{array}{c}\text { Total senyawa fenol } \\
\left({ }^{\mathrm{a}} \mathrm{mg} \text { per GAE/g ekstrak }\right)\end{array}$ & $\begin{array}{c}\text { Total senyawa flavonoid } \\
\left({ }^{\mathrm{a}} \mathrm{mg} \text { per QE/g ekstrak }\right)\end{array}$ \\
\hline 1. & Metanol & $2.328 \pm 0.003$ & $5.00 \pm 0.04$ \\
\hline 2. & Etanol & $1.769 \pm 0.001$ & $3.73 \pm 0.08$ \\
\hline 3. & Aseton & $1.535 \pm 0.004$ & $3.31 \pm 0.06$ \\
\hline 4. & Etil asetat & $1.318 \pm 0.002$ & $3.70 \pm 0.04$ \\
\hline 5. & Aquadest & $0.535 \pm 0.002$ & $1.29 \pm 0.03$ \\
\hline
\end{tabular}


Quercetin Equivalence (QE). Analisisnya menunjukkan bahwa terdapat jumlah signifikan dari kedua senyawa tersebut pada masing-masing ekstrak aquadest maupun ekstrak organik dari daun jati cina berada di rentang angka $0.535 \pm 0.002$ sampai $2.328 \pm 0.003 \mathrm{mg}$ per $\mathrm{GAE} / \mathrm{g}$, yang ditunjukkan pada Tabel 2.

\section{PEMBAHASAN}

Obat-obatan herbal telah digunakan oleh banyak orang sebagai alternatif dari obat-obatan kimiawi. Daun jati cina adalah salah satu obat herbal yang telah banyak digunakan di seluruh dunia untuk mengatasi konstipasi. Daun jati cina merupakan salah satu jenis produk laksatif popular di masyarakat, terutama pada lansia (Heaton \& Cripps, 1993). Salah satu komponen bioaktifnya, senosida, memerankan perannya dalam laksatif melalui dua mekanisme tunggal: peningkatan motilitas usus besar dan perubahan absorpsi dan sekresi usus besar yang menyebabkan adanya akumulasi cairan (Soyuncu et al., 2008). Peningkatan motilitas usus disebabkan oleh adanya kerusakan tidak langsung pada sel epitel karena pelepasan sitokin (von der Ohe, Camilleri, Kvols, \& Thomforde, 1993). Efek anthranoid pada sekresi dan absorpsi secara umum dipicu oleh interaksi antara zat laksatif dan sel epitel (Van Hoestenberghe et al., 1992).

Penghambatan langsung pada system $\mathrm{Na}^{+} / \mathrm{K}^{+}$-ATPase mencegah absorpsi natrium dan air dari lumen usus ke aliran darah (Soyuncu et al., 2008). Adanya gangguan pada pertemuan antara sel epitel menyebabkan adanya peningkatan permeabilitas epitel dan peningkatan sekresi cairan dan elektrolit (van Gorkom, de Vries, Karrenbeld, \& Kleibeuker, 1999).
Daun jati cina telah banyak digunakan sebagai laksatif dengan dosis 0,6 sampai 2 gram/hari, dengan dosis harian senosida B dari 20-30 mg (Soyuncu et al., 2008). Daun jati cina tidak boleh digunakan pada dosis yang lebih tinggi bila tidak ada indikasi ataupun dalam penggunaan jangka panjang (Blumenthal et al., 2000). Konsumsinya yang berlebihan dapat menyebabkan kehilangan cairan, hipokalemia, dan diare (Gattuso \& Kamm, 1994). Efek samping lainnya dapat berupa nyeri abdomen, peningkatan berlebih peristaltik usus, dan ruam popok (Spiller et al., 2003).

Senna banyak digunakan dalam dosis yang relatif rendah tanpa menimbulkan masalah kesehatan yang besar; senna juga digunakan dalam dosis besar untuk pembersihan kolon sebelum pemeriksaan radiologi. Penggunaan dosis yang besar sebelum pemeriksaan radiologi sebenarnya cukup aman, namun daun jati cina tidak boleh digunakan bila terdapat faktor predisposisi ruptur kolon pada pasien (Aronson, 2016). Pasien dengan penyakit Crohn, kolitis ulseratif, apendisitis, obstruksi usus, dan nyeri abdomen tidak boleh diberikan jati cina (Blumenthal et al., 2000).

Keamanan jati cina selama hamil dan menyusui masih dipertanyakan meskipun jati cina menjadi pilihan laksatif stimulant selama kehamilan dan proses menyusui (Gattuso \& Kamm, 1994). Namun, banyak publikasi masih menyarankan untuk menghindari konsumsinya selama kehamilan (Faber \& Strenge-Hesse, 1989; Mengs, 1986; Newall, Anderson, \& Phillipson, 1996). Badan pengawas obat dan makanan Amerika Serikat The United States Food and Drug Administration 
memberikan label kategori $\mathrm{C}$ untuk seluruh produk jati cina.

Tidak ada bayi yang dilaporkan mengalami diare selama disusui ibu yang mengonsumsi laksatif jati cina (American Academy of Pediatrics, 2005; Faber \& Strenge-Hesse, 1989). Penggunaan daun jati cina sebagai salah satu alternatif agen laksatif dalam menangani konstipasi pada anak juga masih dianggap aman namun perlu diperhatikan efek sampingnya seperti nyeri abdomen dan diare pada administrasi pertama juga dermatitis yang mungkin terjadi bila pasien butuh dosis yang lebih tinggi (VilanovaSanchez et al., 2018). Namun, dikutip dari Soyuncu et al. (2008), U.S. Food and Drug Administration kurang merekomendasikan penggunaannya untuk anak di bawah usia 2 tahun.

Konsumsi berlebih daun jati cina dapat menyebabkan keluhan abdomen ringan, seperti kram dan nyeri. Efek samping lainnya yang mungkin terjadi adalah perubahan warna urin dan kongesti hemoroid. Penggunaan jangka panjang dan overdosis dapat menyebabkan diare, penurunan drastic kadar elektrolit terutama kalium, kerusakan epitel usus, serta kerusakan saraf otonom yang dapat menyebabkan terganggunya fungsi usus. Penyalahgunaan daun jati cina juga telah dikaitkan dengan kasus melanosis coli, tapi kesembuhan muncul 8-11 bulan pasca penghentian konsumsi (Aronson, 2016).

Kerusakan hepar akut dan kronis mungkin terjadi setelah konsumsi produk alkaloid dari jati cina (Stickel \& Schuppan, 2007; Stickel, Seitz, Hahn, \& Schuppan, 2001). Efek hepatotoksisitasnya jarang dilaporkan, tetapi dapat dijelaskan melalui paparan jumlah abnormal dari metabolit toksik glikosida anthraquinone terhadap hepar. Trombosis vena porta dapat terjadi akibat efek hepatotoksisitasnya ini (Soyuncu et al., 2008). Komplikasikomplikasi yang mungkin juga terjadi pasca penyalahgunaan daun jati cina adalah hepatitis, clubbing finger, dan osteopati hipertropi (Aronson, 2016).

\section{SIMPULAN}

Konstipasi merupakan salah satu gangguan gastrointestinal yang umum terjadi pada semua kelompok usia, namun apabila tidak ditangani dapat menyebabkan penurunan kualitas hidup dari penderita serta beresiko menimbulkan komplikasi kesehatan. Salah satu agen laksatif yang dapat digunakan dalam menangani konstipasi adalah daun jati cina, yang mana jati cina ini sendiri sudah banyak dimanfaatkan, terutama buah dan daunnya, untuk mengobati beberapa penyakit lain selain konstipasi. Salah satu komponen bioaktif yang berperan dalam aktivitas laksatifnya adalah senosida.

Senosida dalam daun jati cina dapat mengurangi gejala konstipasi dengan mekanismenya berupa meningkatkan motilitas usus besar dan mengubah absorpsi dan sekresi usus besar yang menyebabkan adanya akumulasi cairan. Meskipun menunjukkan manfaat yang luar biasa sebagai agen laksatif, beberapa efek samping yang ringan mulai dari diare dan nyeri atau kram abdominal, sampai yang parah seperti efek hepatotoksisitasnya, perlu dipertimbangkan dalam pemberian dosis dan lama pengobatan untuk konsumsi sebagai pengobatan konstipasi.

\section{DAFTAR PUSTAKA}

Ahmed, S., Hayat, M., Tahir, M., Mansoor, Q., Ismail, M., Keck, 
K., \& Bates, R. (2016). Pharmacologically active flavonoids from the anticancer, antioxidant and antimicrobial extracts of Cassia angustifolia Vahl. BMC Complement Altern Med, 16(1), 460. doi: $10.1186 / \mathrm{s} 12906-016-1443-\mathrm{Z}$

American Academy of Pediatrics. (2005). The transfer of drugs and other chemicals in to human milk. Retrieved from http://aappolicy.aappublications.o $\mathrm{rg} / \mathrm{cgi} /$ content/full/pediatrics;108/ 3/776\#T6

Aronson, J. K. (2016). Laxatives. In Meyler's Side Effects of Drugs (16th ed., pp. 488-494). Philadelphia: Elsevier. doi: https://doi.org/10.1016/B978-0444-53717-1.00960-4

Balasankar, D., Vanilarasu, K., Preetha, P. S., Umadevi, S. R. M., \& Bhowmik, D. (2013). Senna - A Medical Miracle Plant. Journal of Medicinal Plants Studies, 1(3), 41-47.

Blumenthal, M., Brinckmann, J., \& Goldberg, A. (2000). Herbal Medicine: Expanded Commission E Monographs. Massachusetts: Integrative Medicine Communications.

Brown, J., Isaacs, J., Krinke, U., Lechtenberg, E., Murtaugh, M., Sharbaugh, C., ... Wooldridge, N. (2011). Nutrition Through the Life Cycle (4th ed.). USA: Wadsworth Cengage Learning.

Chien, D., Chu, Y., \& Lee, M. (2010). Anthracenedione Compounds. United States: United States Patent Application Publication.
Claudina, I., Rahayuning, D., \& Kartini, A. (2018). Hubungan Asupan Serat Makanan dan Cairan dengan Kejadian Konstipasi Fungsional Pada Remaja Di SMA Kesatrian 1 Semarang. Jurnal Kesehatan Masyarakat (e-Journal), 6(1), 486-495.

Dharmika, D. (2014). Pendekatan Klinis Penyakit Gastroenterologi. In S. Setiati, I. Alwi, S. W. Aru, M. Simadibrata, B. Setiiyohadi, \& A. F. Syam (Eds.), Buku Ajar Ilmu Penyakit Dalam (6th ed.). Jakarta: Internal Publishing.

Faber, P., \& Strenge-Hesse, A. (1989). Sennahaltiges Laxans: Ubertritt in Muttermilch? [Senna-containing laxatives: excretion in the breast milk?].

Geburtshilfe Frauenheilkd, 49(11), 958-962. doi: $10.1055 / \mathrm{s}-2008-1036117$

Gattuso, J., \& Kamm, M. (1994). Adverse effects of drugs used in the management of constipation and diarrhoea. Drug Saf, 10(1), 47-65. doi: 10.2165/00002018199410010-00004

Gwee, K., Ghoshal, U., Gonlachanvit, S., Chua, A., Myung, S., Rajindrajith, S., ... Abdullah, M. (2013). Primary Care Management of Chronic Constipation in Asia: The ANMA Chronic Constipation Tool. Journal of Neurogastroenterology and Motility, 19(2), 149-160. doi: https://doi.org/10.5056/jnm.2013. 19.2.149

Heaton, K., \& Cripps, H. (1993). Straining at stool and laxative taking in an English population. Dig Dis Sci, 38(6), 1004-8. doi: 10.1007/BF01295713 
Lemli, J. (1988). Metabolism of sennosides - an overview. Pharmacol, 36(suppl. 1), 126128. doi: $10.1159 / 000138431$

Mengs, U. (1986). Reproductive toxicological investigations with sennosides.

Arzneimittelforschung, 36(9), 1355-1358.

Newall, C., Anderson, L., \& Phillipson, J. (1996). Herbal Medicines. London: Pharmaceutical Press.

Ramchander, Jalwal, P., \& Middha, A. (2017). Recent advances on senna as a laxative: A comprehensive review. Journal of Pharmacognosy and Phytochemistry, 6(2), 349-353.

Sari, A. (2016). Hubungan Asupan Serat dan Aktivitas Fisik dengan Kejadian Konstipasi pada Lansia di Kota Madiun. Universitas Airlangga.

Sari, A. D. K., \& Wirjatmadi, B. (2017). Hubungan Aktivitas Fisik Dengan Kejadian Konstipasi Pada Lansia Di Kota Madiun. Media Gizi Indonesia, 11(1), 40. doi: 10.20473/mgi.v11i1.40-47

Setyani, F. (2012). Dampak Minuman Probiotik dalam Upaya Pencegahan Konstipasi pada Pasien Infarct Myocard di RSPAD Gatot Soebroto Jakarta. Universitas Indonesia.

Soyuncu, S., Cete, Y., \& Nokay, A. (2008). Portal vein thrombosis related to Cassia angustifolia. Clin Toxicol (Phila), 46(8), 774-777. doi: 10.1080/15563650701682097

Spiller, H., Winter, M., Weber, J., Krenzelok, E., Anderson, D., \&
Ryan, M. (2003). Skin breakdown and blisters from senna-containing laxatives in young children. Ann Pharmacother, 37(5), 636-639. doi: 10.1345/aph.1C439

Stickel, F., \& Schuppan, D. (2007). Herbal medicine in the treatment of liver diseases. Dig Liver Dis, 39(4), 293-304. doi: 10.1016/j.dld.2006.11.004

Stickel, F., Seitz, H., Hahn, E., \& Schuppan, D. (2001). Hepatotoxizität von Arzneimitteln pflanzlichen Ursprungs [Liver toxicity of drugs of plant origin]. Z Gastroenterol, 39(3), 225-232, 234-237. doi: 10.1055/s-200111772

van Gorkom, B., de Vries, E., Karrenbeld, A., \& Kleibeuker, J. (1999). Review article: anthranoid laxatives and their potential carcinogenic effects. Aliment Pharmacol Ther, 13(4), 443-452. doi: $10.1046 / \mathrm{j} .1365-$ 2036.1999.00468.x

Van Hoestenberghe, A., De Witte, P., Geboes, K., Eyssen, H., Nijs, G., \& Lemli, J. (1992). The effect of rhein and rhein anthrone on intestinal fluid transport and on large intestine transit in germ-free rats. Eur J Pharmacol, 212(1), 121-123. doi: 10.1016/00142999(92)90084-h

Vidiastri, S. (2012). Evaluasi Efek Teh Jati Cina (Cassia angustifolia Vahl.) Terhadap Kadar Trigliserida Plasma Pada Tikus Putih (Rattus norvegicus) Obes. Universitas Muhammadiyah Yogyakarta.

Vilanova-Sanchez, A., Gasior, A. C., Toocheck, N., Weaver, L., Wood, 
R. J., Reck, C. A., ... Levitt, M. A. (2018). Are Senna based laxatives safe when used as long term treatment for constipation in children? J Pediatr Surg, 53(4), 722-727. doi: 10.1016/j.jpedsurg.2018.01.002

von der Ohe, M., Camilleri, M., Kvols, L., \& Thomforde, G. (1993). Motor dysfunction of the small bowel and colon in patients with the carcinoid syndrome and diarrhea. N Engl J Med, 329(15), 1073-1078.

10.1056/NEJM199310073291503

Wang, X., Gao, P., Menéndez-Arias, L., Liu, X., \& Zhan, P. (2017). Update on Recent Developments in Small Molecular HIV-1 RNase H Inhibitors (2013-2016): Opportunities and Challenges. Current Medical Chemistry, 25(14), 1-21. doi: $10.2174 / 09298673246661701131$ 10839 
Jurnal Penelitian Perawat Profesional, Volume 3 No 1, Februari 2021 Hal 41 - 50 Global Health Science Group 